\title{
Erratum to: An Additive Subfamily of Enlargements of a Maximally Monotone Operator
}

\author{
Regina S. Burachik ${ }^{1}$ - Juan Enrique Martínez-Legaz ${ }^{2}$. \\ Mahboubeh Rezaie $^{3}$ - Michel Théra ${ }^{4,5}$
}

Published online: 7 September 2015

(C) Springer Science+Business Media Dordrecht 2015

\section{Erratum to: Set-Valued Var. Anal (2015) DOI 10.1007/s11228-015-0340-9}

In the proof of Theorem 2.2 of [1], the authors would like to replace the text: "Bauschke and Wang [2, Theorem 5.7] proved that every maximally monotone operator admits an autoconjugate representation", by the following one: "Svaiter proved in [36, Proposition 2.2 and Theorem 2.4] that for every maximally monotone operator $T$, there exists $h \in \mathcal{H}(T)$ such that $h$ is auto conjugate. See also Bauschke and Wang [2, Theorem 5.7]."

The online version of the original article can be found at http://dx.doi.org/10.1007/s11228-015-0340-9.

\section{Michel Théra}

michel.thera@unilim.fr

Regina S. Burachik

regina.burachik@unisa.edu.au

Juan Enrique Martínez-Legaz

Juan-Enrique.Martinez-Legaz@uab.cat

Mahboubeh Rezaie

mrezaie@sci.ui.ac.ir

1 School of Information Technology and Mathematical Sciences, University of South Australia, Mawson Lakes, SA 5095, Australia

2 Departament d'Economia i d'Història Econòmica, Universitat Autònoma de Barcelona, Barcelona, Spain

3 University of Isfahan, Isfahan, Iran

4 Laboratoire XLIM, Université de Limoges,123, Avenue Albert Thomas, 87060 Limoges Cedex, France

5 Centre for Informatics and Applied Optimisation, Federation University, Mount Helen Campus, PO Box 663 Ballarat, VIC 3353, Australia 
We are very grateful to Heinz $\mathrm{H}$. and Benar F. for their comments and corrections on an earlier version of this manuscript. H. H. Bauschke kindly indicated to us an additional reference for Remark 2.5, while B. F. Svaiter kindly indicated that the results in [36] constitute the earliest proof of the "only if" part of Theorem 2.2.

\section{References}

1. Burachik, R.S., Martínez-Legaz, J.-E., Rezaie, M., Théra, M.: An additive subfamily of enlargements of a maximally monotone operator. Set-Valued Anal. (This issue), 1-23 (2015) 